\section{MODELO CONCEITUAL DILAM: integração entre arquivos, bibliotecas e museus}

\author{
Ana Carolina Simionato* \\ Plácida Leopoldina Ventura Amorim da Costa Santos
}

RESUMO: Os princípios descritivos em arquivos, bibliotecas e museus apresentam procedimentos diversificados e condizentes as formas de representação de seus recursos principalmente em relação à descrição do conteúdo imagético. Dessa forma, a problemática de pesquisa envolve a questão de como promover a integração dos contextos da Arquivologia, Biblioteconomia e Museologia para o recurso imagético digital? A proposta de integração entre os contextos busca a convergência dos dados da imagem tratada na Arquivologia, Biblioteconomia e Museologia, beneficiando a recuperação e localização dos recursos pelo usuário. Aponta $\circ$ meio digital e os princípios descritivos dos três contextos como fatores que subsidiam os estudos e desenvolvimento de um modelo conceitual. Sendo assim, objetivo desse trabalho é apresentar os resultados dessa proposta, por meio da construção do modelo conceitual Digital Images for Libraries, Archives and Museums (DILAM) enfatizando as suas entidades e os atributos responsáveis pela integração aos contextos e ao recurso imagético digital. Metodologicamente constitui de uma pesquisa teórica aplicada e exploratória. Aborda-se as entidades e atributos do modelo conceitual DILAM, além dos grupos referentes a integração dos contextos e as propriedades do conteúdo imagético. Considera-se que essa estrutura é apresentada no diagrama da integração aplicável no ambiente digital em que bibliotecas, arquivos e museus possam cooperar a partir do reuso dos dados e reduzindo o retrabalho da descrição dos recursos imagéticos digitais.

Palavras-chave: Imagem digital. Representação da informação. Metadados.
* Doutora em Ciência da Informação pela Universidade Estadual Paulista Júlio de Mesquita Filho, Brasil. Professora do Departamento de Ciência da Informação da Universidade Federal de São Carlos, Brasil. Docente permanente do Programa de Pós-Graduação em Ciência da Informação da Universidade Federal de São Carlos, Brasil. E-mail: acsimionato@ufscar.br.

** Doutora em Lingüística pela Universidade de São Paulo, Brasil. Livre-docência da Universidade Estadual Paulista Júlio de Mesquita Filho, Brasil. Professora da Universidade Estadual Paulista Júlio de Mesquita Filho, Brasil. Doente permanente do Programa de Pós-Graduação em Ciência da Informação da Universidade Estadual Paulista Júlio de Mesquita Filho, Brasil. E-mail: placida@marilia. unesp.br.

\section{INTRODUÇÃO}

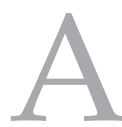

s novas possibilidades do ambiente digital propiciam a revitalização de vários aspectos da Ciência da Informação, incluindo as questões atreladas aos processos de organização e representação da informação. Como também, o desenvolvimento do recurso imagético para o meio digital pluralizou as formas de captura e de veiculação de conteúdo, expandindo as necessidades de divulgação e acesso em repositórios, banco de imagens e catálogos.
Nesse cenário, a representação do recurso informacional deve corresponder a forma expressa em sua retratação, isso condiz que o registro da imagem deve estar adequadamente tratado de acordo com seus usuários. Sendo o recurso informacional definido como "[...] a informação objetivada [...] em uma estrutura analógica e/ou digital, com valor informacional que caracteriza a sua concepção intelectual expressa na corporificação de manifestações estruturadas na forma de itens." (SANTOS; SIMIONATO; ARAKAKI, 2014, p. 148). 
O registro deve expressar a forma de retratação, condizente ao tratamento e conceitos da área de Ciência da Informação, refletindo sob as questões de domínio direcionadas por Glushko (2013) e Svenonius (2009). O domínio pode ser salientado pelas características detalhadas de cada contexto, e elencadas principalmente pelos princípios descritivos.

O recurso imagético é caracterizado pela sua presença em diversos tipos de acervos e instituições, como exemplo arquivos, bibliotecas e museus, além das galerias de arte. O grande impacto dessa diversificação, incide ao valor atribuído como patrimônio artístico, cultural, preservação da memória, de comprovação, entre outros.

Por essa razão, julga-se necessário refletir sobre os movimentos de integração entre estes contextos já realizados por Homulos (1990), Smit e Barreto (2002), Smit (2009), Guimarães (2008), Tanus e Araújo (2012) e Marcondes (2012). A especificidade dos recursos imagéticos necessita de estudo que explorem a conciliação da representação em cada contexto como em arquivos, bibliotecas e museus que pode ser utilizado. Assim, esse estudo questiona: como promover a integração dos contextos da Arquivologia, Biblioteconomia e Museologia para o recurso imagético digital por meio dos princípios descritivos?

A integração entre os contextos é uma proposta que busca a convergência dos dados imagéticos na Arquivologia, Biblioteconomia e Museologia, beneficiando a recuperação e localização dos recursos pelo usuário. Para tanto, é considerado as diferenças organizacionais e as necessidades da análise documental realizada em cada unidade informacional.

Considera que o ambiente digital é um meio convergente de diversos usuários, independentemente do vínculo institucional formado, ou seja, o ambiente digital pode agrupar diferentes grupos informacionais. Por esse motivo, o meio digital com os princípios descritivos dos contextos arquivístico, biblioteconômico e museológico são fatores que subsidiam a construção de um modelo conceitual, que possa ser relacionado com os atributos de recursos imagéticos em ambientes digitais a partir do seu domínio.

Sendo assim, o objetivo desse trabalho é expor o desenvolvimento do modelo conceitual
Digital Images for Libraries, Archives and Museums (DILAM) enfatizando as suas entidades e os atributos responsáveis pela integração aos contextos e ao recurso imagético digital.

\section{PROCEDIMENTOS METODOLÓGICOS}

A pesquisa é classificada como natureza teórico-aplicada e qualitativa, objetivando gerar novas possibilidades para construção de registros informacionais na representação e organização de imagens digitais. Em relação aos objetivos do trabalho para integração dos contextos arquivístico, biblioteconômico e museológico, essa pesquisa é classificada como exploratória. Aos procedimentos técnicos recorre-se a pesquisa bibliográfica, com o levantamento realizado em nível nacional e internacional em fontes de pesquisa primárias, secundárias e terciárias.

Em relação ao levantamento bibliográfico, as fontes utilizadas no levantamento bibliográfico foram: Biblioteca Digital Brasileira de Teses e Dissertações (BDTD), Base de Dados Referenciais de Artigos de Periódicos em Ciência da Informação (BRAPCI), Portal de Periódicos da Capes, Google Acadêmico, Scientific Electronic Library Online (SciELO) e a Web of Science, tendo como resultados artigos, teses e dissertações, capítulos de livros e livros.

O método escolhido para o desenvolvimento do modelo foi a modelagem Entidade-Relacionamento, já trabalhada nos Requisitos Funcionais para Dados Imagéticos Digitais (RFDID) por Simionato (2012), sendo sua base espelhada na estrutura dos Functional Requirements for Bibliographic Records (FRBR).

\section{A IMAGEM E A DESCRIÇÃO NA ARQUIVOLOGIA, BIBLIOTECONOMIA E MUSEOLOGIA}

O recurso imagético teve uma ampla proporção de aceitação e utilização de suas criações pelo meio digital, ocasionado pelas redes sociais. Entre as características relativas à gênese digital podem ser destacados os dados Exchangeable Image File Format (EXIF) ou mesmo, as diferentes extensões que o recurso pode incidir. As extensões podem ser nomeadas por 
imagens vetoriais, ou seja, imagens geradas a partir de descrições geométricas de formas e se diferencia das imagens bitmap ou mapa de bits; ou raster, que são geradas a partir de pontos minúsculos diferenciados por suas cores.

Entretanto, ressalta-se a importância para a adequação da descrição relacionada ao tipo de ambiente inserido, caso isso não seja considerado ocorrerá problemas em sua localização e consequentemente o usuário não recuperará o que deseja. Sánchez Vigil (2006) observa que o documento imagético está disperso nos acervos apresentando variedades (fotografias, negativos, imagens digitais) e dependentes do tipo de instituição que as incorpora no acervo são diferenciadas pela sua aplicação e função. Após a aquisição, as imagens são distinguidas pelo seu assunto, tratadas de modo aleatório e pouco utilizados os vocabulários controlados e a indexação, e em raros os casos pela autoria e título. (VIGIL, 2006).

Para possibilitar a localização, acesso e recuperação das imagens vários tratamentos informacionais e criações computacionais são necessárias, uma delas é a padronização dos atributos, realizadas por instrumentos de descrição. Mas antes da padronização dos atributos, os princípios descritivos também devem ser salientados para que a semântica entre os dados seja contemplada.

Durante o estudo da descrição de imagens na Arquivologia, foi identificado as correntes teóricas e metodológicas que definem as formas representação no ciclo de vida dos documentos. Nas correntes mais tradicionais do campo, como a diplomática arquivística e a pós-custodial, aponta-se que a descrição somente é realizada na fase permanente. Ao contrário da corrente da arquivística integrada, proposta por Rousseau e Couture (1998) a descrição inicia-se a partir da criação/produção do documento na instituição, preservando os atributos já definidos na sua fase corrente.

A arquivística integrada é uma forma gerada e conduzida ao propósito da organização, dentro destas funções, pode ser concentrada conforme às formalidades da descrição e da classificação. (ROUSSEAU; COUTURE, 1998). Essa corrente foi definida para essa pesquisa por garantir a unicidade das intervenções nos documentos, aplicando o princípio das três idades - fases corrente, intermediária e permanente, e ainda caracterizando pela construção lógica dos metadados descritivos para o arranjo e da ordem original dos subgrupos, denominadas como séries, dos documentos.

A utilização da corrente da arquivística integrada assegura o acesso aos documentos, desde a fase inicial e ainda, poupa o retrabalho do profissional arquivista evitando novas descrições ao longo do processo documental. Ressalva que na arquivística integrada, os fundamentos apoiam o tratamento descritivo para o Gerenciamento Eletrônico de Documentos (GED) definidos por Rousseau e Couture (1998).

No entanto, os instrumentos arquivísticos mais utilizados como a International Standard Archival Description General - ISAD (G) não acompanharam o mesmo desenvolvimento organizacional e representacional junto as novas possibilidades do meio digital, assim não conseguem explorar todo o potencial e seus alinhamentos com o desenvolvimento de seus modelos conceituais, como o Conceptual Model for Archival Description (CMAD) e as iniciativas Modular Requirements for Records Systems (MoReq) e Modelo de Entidades e Relacionamentos do e-ARQ Brasil.

Já a Biblioteconomia, pelo seu próprio desfecho histórico apresenta uma maior dinâmica em relação aos instrumentos descritivos e aos modelos conceituais. Guinchat e Menou (1994"source":"Open WorldCat", "eventplace":"Brasilia", "abstract":"Os tipos de documentos. As bibliografias e as obras de referencia: a literatura secundaria. A selecao e a aquisicao. O armazenamento dos documentos. A descricao bibliografica. A descricao de conteudo. As linguagens documentais. A classificacao. A indexacao. O resumo. Os catalogos e os ficharios. As instalacoes e os equipamentos. A informatica nas unidades de informacao. A unidade de informacao e as novas tecnologias. A industria da informacao. A pesquisa da informacao. A avaliacao dos sistemas de armazenamento e de pesquisa da informacao. Os tipos de unidades de informacao e as redes. Os servicos de difusao da informacao. Os programas e sistemas internacionais de informacao. A normalizacao. A gestao e as politicas de uma unidade de informacao. A gestao e as politicas nacionais e internacionais de informacao. Os usuarios. A formacao profissional. A profissao. A pesquisa em ciencias e tecnicas da informacao. 
Complemento bibliografico.", "ISBN":"97885-7013-050-1","note":"OCLC: 693429241","la nguage":"Portuguese", "author":[[“family": "Guinchat","given":"Claire" $\},\{$ "family":"M enou", "given":"Michel" \}],"issued":\{"dateparts":[[“1994"]]\}\}\}],"schema":"https://github. com/citation-style-language/schema/raw/ master/csl-citation.json"\} , p. 101) afirmam que a catalogação deve "[...] fornecer uma representação do documento que é descrito de uma forma única e não ambígua, o que permite identificá-lo, localizá-lo, representá-lo nos catálogos correspondentes e recuperá-lo."

A catalogação permite que o catálogo possa multidimensionar as escolhas, para que o usuário encontre o material desejado. Segundo Santos e Pereira (2014, p. 71)

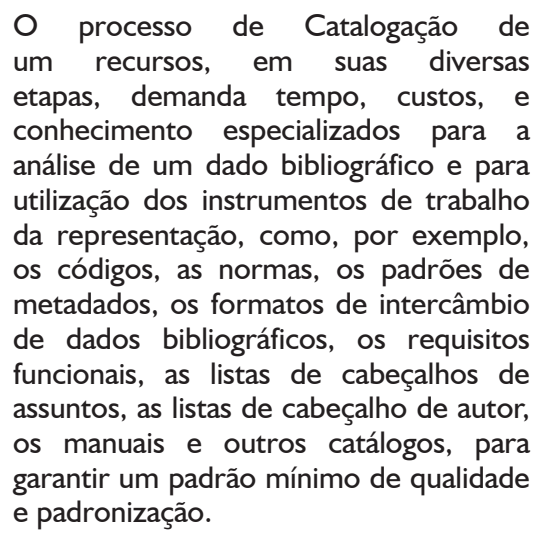

A catalogação, processo já consolidado na Biblioteconomia, além de garantir a unicidade ao recurso informacional em uma forma sucinta e estruturada dos dados, apresenta certas características que contemplam a coerência para o tratamento adequado dos recursos informacionais. As disposições da catalogação estão relacionadas as novas formas de representação como o Functional Requirements for Bibliographic Records (FRBR), por exemplo. Com a concepção do FRBR, o entendimento do processo de representação do recurso informacional foi revisto e com isso, novos relacionamentos entre os recursos informacionais foram possíveis.

Essa percepção influenciou diretamente a estrutura de alguns códigos de catalogação como a International Standard Bibliographic Description (ISBD) em sua versão consolidada e o AngloAmerican Cataloguing Rules, second edition revised (AACR2r) que se diferenciam por suas estruturas e tipos de recursos como livros e materiais cartográficos. Dessa forma, a ISBD a que havia diversas publicações transformou em apenas um único manual e o AACR2r que subdividia seus capítulos direcionadas a descrição de um tipo de recurso está sendo substituído pelo Resource Description and Access (RDA).

Já a Museologia é reconhecida pela sua instituição condizer a coleção e a responsabilidade de induzir a ampliação dos conhecimentos sobre a humanidade e suas técnicas, ou seja, toda forma representacional reluz as fontes informacionais daquela determinada imagem digital e de sua coleção. Assim, "[...] liga-se diretamente à morfologia do objeto, isto é, diz respeito a materiais e técnicas de confecção, a formas, ornamentos, a partes constituintes, a funções utilitárias para as quais foi concebido e a significados simbólicos relacionados às formas materiais de representação." (BARBUY, 2002, p. 71).

O catálogo na museologia "[...] trata-se de um meio de comunicação típico e objetivo para difusão de suas propostas. Através dele o museu comunica os estudos e pesquisa que vêm sendo realizados sobre um determinado aspecto, utilizando seus próprios meios de interpretação [...]". (CAMARGO-MORO, 1986, p. 225).

Os instrumentos de representação na Museologia específicos são pouco abordados, pela diversidade de campos que são necessários para os registros. Mesmo que nem todos sejam preenchidos, os campos necessários são: o tipo do material, técnica utiliza, procedência, história de exposição, as considerações de instalação e valor de avaliação.

O registro nos museus é um processo muito parecido com a catalogação em bibliotecas. Os registros são criados para que conduzam a organização do catálogo e estabelece o controle para os aspectos organizacionais sobre todos os recursos informacionais da instituição. Ao compor o registro Zoreda (1988) ressalta que a documentação museológica deve cobrir todo o campo documental e deve ser feito o registro de todo o acervo da instituição. Diretamente a evolutiva dos princípios descritivos dos museus, o Conceptual Reference Model (CRM) fornece definições e uma estrutura formal para descrever conceitos implícitos e explícitos e relacionamentos usados no patrimônio cultural. 


\section{MODELO CONCEITUAL DILAM}

Com o objetivo equivaler para que possa integrar os princípios descritivos dos contextos da Arquivologia, Biblioteconomia e Museologia, o modelo DILAM corrobora de tal forma que não trate de forma diminutiva cada instância, mas sim de forma colaborativa e seja complementar ao planejamento de dados estruturados em um modelo conceitual.

Assim, o modelo DILAM foi desenvolvido a partir dos estudos realizado por Simionato (2015) elaborada a partir de três etapas, que constituem: 1) definição de requisitos funcionais para os usuários, 2) definição dos metadados apropriados ao recurso imagético digital e 3) definição das entidades e criação do modelo DILAM.

A definição dos requisitos funcionais foi baseada no aprofundamento dos estudos sobre o recurso imagético digital, como também sobre cada uma das necessidades de cada contexto e seus usuários.

Os requisitos funcionais na Ciência da Informação, também são encontrados com a terminologia user tasks ou tarefas do usuário. Essas tarefas coincidem com as propriedades que cada particularidade da modelagem deve priorizar. Outro ponto considerado foi a harmonização entre o os modelos conceituais já finalizados na área de Ciência da Informação, como o FRBR e o Requisitos Funcionais para Recursos Imagéticos Digitais (RFDID) proposto por Simionato (2012).

Dessa forma, os requisitos conceituais previstos na modelagem e caracterizados no modelo DILAM, foram planejados a partir dos modelos conceituais e propostas da Arquivologia, Biblioteconomia e Museologia, que incluem Functional Requirements for Bibliographic Records (FRBR), Autoridade (FRAD) e Assunto (FRSAD), o domínio da arquivístico, Conceptual Model for Archival Description (CMAD) e o Modular Requirements for Records Systems (MoReq) e o domínio museológico, Conceptual Reference Model (CRM).

Assim, os requisitos funcionais para o DILAM são:

- Encontrar materiais que correspondem aos critérios estabelecidos de pesquisa do usuário;

- Identificar uma entidade;
- Selecionar uma entidade que é adequado para as necessidades do usuário;

- Explorar os recursos imagéticos de uma coleção, utilizando atributos e relações entre os recursos, usando atributos e relacionamentos;

- Escolher os assuntos para que possam encontrar as imagens desejadas, usando atributos e relacionamentos;

- Reconhecer as responsabilidades de criação de um recurso imagético digital, e buscar as autorias, usando atributos e relacionamentos; e

- Obter o recurso imagético, selecionado e identificado.

O segundo passo foi a escolha dos metadados apropriados foi derivado do método crosswalk (PIERRE; LAPLANT, 1999). Os crosswalks são usados para "[...] comparar elementos de metadados de um esquema ou elemento definido para um ou mais outros esquemas [...]" (BACA, 2008, p. 47, tradução nossa) e também da metodologia BEAM proposto por Santos, Simionato e Arakaki (2014).

Os padrões de metadados utilizados no crosswalk foram: Anglo-American Cataloguing Rules, second edition revised (AACR2r), Cataloging Cultural Objects (CCO), Categories for the Description of Works of Art (CDWA), Categories for the Description of Works of Art Lite (CDWA Lite), Describing Archives: a content standard (DACS), Dublin Core (DC), Encoded Archival Description (EAD), Graphic Materials, International Standard Archival Description General (ISAD $(\mathrm{G}))$, International Standard Bibliographic Description, consolidated edition (ISBD), Resource Description and Access (RDA), Rules for Archival Description (RAD) e SPECTRUM.

Os resultados dos crosswalks foram base para o desenvolvimento do último passo, a criação das entidades para o modelo DILAM. Inicialmente, foi determinado que as entidades da modelagem entidade-relacionamento, no escopo da desvinculação de um registro monolítico sem relacionamentos, como na estrutura MARC 21, para um registro construído a partir de integrações da imagem digital, principalmente, entre áreas.

O modelo conceitual DILAM é visualizado pela figura 1 . 
Figura 1 - Modelo Conceitual DILAM

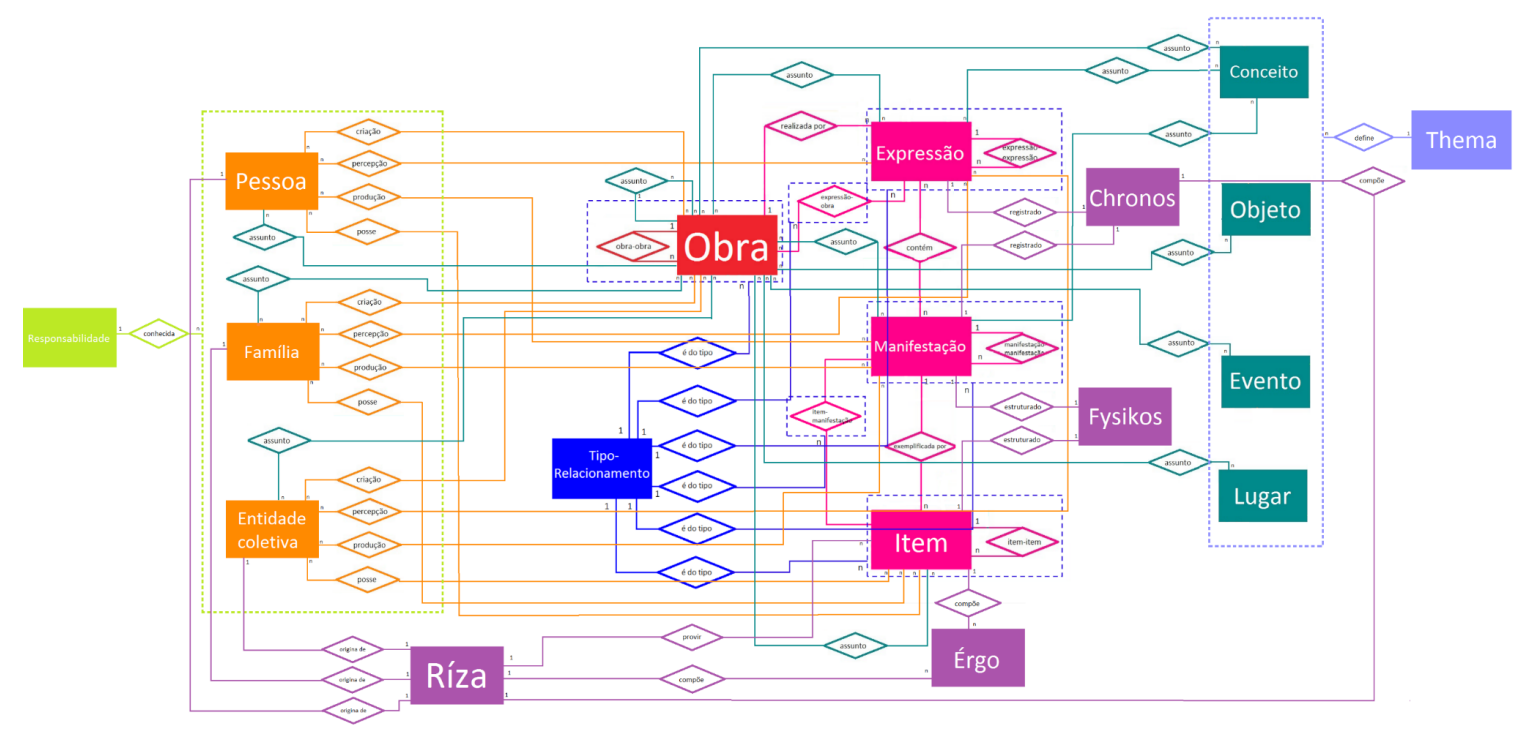

Fonte: Simionato (2015, p. 121).

Como visto na figura 1 , as entidades são compatíveis com as entidades já compostas da família FRBR e por isso as entidades foram mantidas, Obra, Expressão, Manifestação, Item (Grupo 1), Pessoa, Família, Entidade Coletiva (Grupo 2), Conceito, Objeto, Evento e Lugar (Grupo 3).

Outras entidades foram criadas para acrescentar e subsidiar alguns relacionamentos entre as entidades. Tipo-Relacionamento, que descreve a que tipo de relacionamento pertence o relacionamento complementar as entidades do Grupo 1 e Obra, Responsabilidade, entidade que relaciona ao controle de autoridade do Grupo 2 e Obra, e Thema, entidade que relaciona ao controle de assunto do Grupo 3 e Obra.

Para a integração entre os contextos arquivístico, biblioteconômico e museológico, a modelagem conceitual precisou que algumas entidades fossem incorporadas ao seu escopo. Desse modo, trariam os requisitos específicos de cada contexto. Entre os modelos de Museologia e Arquivologia, algumas características se mostram importantes e comuns, em relação a descrição: tempo, propriedades físicas, origem do recurso informacional (procedência e proveniência) e os processos técnicos dos recursos imagéticos, como a classificação de documentos. Outro destaque foi aos 'fundos', 'séries', 'arquivos' do documento, mas é compreendido que nesse modelo conceitual insere-se as abstrações de uma obra, expressão e manifestação, por serem propriedades de organização do recurso. Por isso, foram criadas quatro novas entidades que relacionam entre as outras já mencionadas. As entidades são: Chronos (tempo), Fysikos (propriedades físicas), Rízo (origem o recurso) e Érgo (atividades técnicas). (SIMIONATO, 2015).

Para tanto, um melhor entendimento sobre as entidades do modelo DILAM será feito a partir do quadro 1, que descreve cada uma das entidades e seus relacionamentos. 
Quadro 1 - Descrição das entidades do modelo conceitual DILAM

\begin{tabular}{|c|c|}
\hline $\begin{array}{c}\text { Entidades do modelo } \\
\text { DILAM }\end{array}$ & Descrição \\
\hline Obra & $\begin{array}{l}\text { É a abstração da concepção } \\
\text { intelectual do autor, ou seja, é uma } \\
\text { entidade definida como o que autor } \\
\text { pensou antes de se tornar concreto. } \\
\text { Nesta entidade, a concepção de } \\
\text { um recurso imagético não está } \\
\text { ligada a uma concepção primária, } \\
\text { inicialmente, o autor não compõe a } \\
\text { obra em um suporte, mas somente, } \\
\text { a conceitua. }\end{array}$ \\
\hline Expressão & $\begin{array}{l}\text { Condiz a realização intelectual ou } \\
\text { artística, ou seja, podemos dizer } \\
\text { que é a elaboração da obra, é } \\
\text { quando o autor já feito a concepção } \\
\text { de uma obra decide traduzi-la na } \\
\text { forma imagética e se preocupa } \\
\text { em como será a imagem. Possui } \\
\text { o relacionamento de 'estar em', } \\
\text { 'incorporar' e 'conter' com a } \\
\text { manifestação. }\end{array}$ \\
\hline Manifestação & $\begin{array}{l}\text { A Manifestação atribui a forma } \\
\text { física e concreta da expressão de } \\
\text { uma obra. Pode ser uma imagem } \\
\text { analógica, digital ou as duas ao } \\
\text { mesmo tempo, será o suporte } \\
\text { de registro da imagem. Possui o } \\
\text { relacionamento de 'exemplificar' } \\
\text { com o item. }\end{array}$ \\
\hline Item & $\begin{array}{l}\text { A imagem que o usuário } \\
\text { encontrará em um catálogo, banco } \\
\text { ou repositório de imagens. }\end{array}$ \\
\hline Tipo-Relacionamento & $\begin{array}{l}\text { Descreve a que tipo de } \\
\text { relacionamento pertence o } \\
\text { relacionamento complementar } \\
\text { as entidades do Grupo } 1 \text { e Obra, } \\
\text { Responsabilidade, entidade } \\
\text { que relaciona ao controle de } \\
\text { autoridade do Grupo } 2 \text { e Obra. } \\
\text { Os relacionamentos podem ser } \\
\text { de adaptação, complemento, } \\
\text { imitação, sucessão, suplemento, } \\
\text { sumarização, transformação e todo } \\
\text { para a parte. }\end{array}$ \\
\hline Pessoa & $\begin{array}{l}\text { É a abstração de um indivíduo, o } \\
\text { principal responsável pela criação, } \\
\text { ou ainda a responsabilidade } \\
\text { da realização de uma obra. Ou } \\
\text { seja, o responsável pela captura } \\
\text { da imagem digital ou por sua } \\
\text { realização. No caso, não é } \\
\text { importante que o fotógrafo seja } \\
\text { amador ou profissional, ou se o } \\
\text { responsável pela criação foi um } \\
\text { telescópio. }\end{array}$ \\
\hline
\end{tabular}

\begin{tabular}{|c|c|}
\hline Família & $\begin{array}{l}\text { A Família é atrelada não a } \\
\text { responsabilidade de criação, mas } \\
\text { a redentora dos direitos autorais } \\
\text { do indivíduo criador. E seus } \\
\text { componentes familiares estarão } \\
\text { ligados a pessoa. Como da mesma } \\
\text { forma é a Entidade coletiva, } \\
\text { contudo, o que difere são as formas } \\
\text { de parentesco dos responsáveis. }\end{array}$ \\
\hline Entidade coletiva & $\begin{array}{l}\text { São as organizações ou grupos } \\
\text { de indivíduos responsáveis } \\
\text { pelo conteúdo intelectual da } \\
\text { imagem digital, inclusive } \\
\text { grupos temporários (encontros, } \\
\text { conferências, reuniões, festivais, } \\
\text { etc.) e autoridades territoriais } \\
\text { como uma federação, um estado, } \\
\text { uma região, entre outros. }\end{array}$ \\
\hline Responsabilidade & $\begin{array}{l}\text { Auxilia na identificação das } \\
\text { principais formas de autoridade } \\
\text { para o usuário. Sua atribuição } \\
\text { deriva-se as necessidades } \\
\text { encontradas no modelo } \\
\text { conceitual FRAD. Logo, atribui } \\
\text { seu relacionamento de uma } \\
\text { entidade ser conhecida por uma } \\
\text { responsabilidade. }\end{array}$ \\
\hline Conceito & $\begin{array}{l}\text { Representa uma noção abstrata } \\
\text { ou uma ideia que podem ser } \\
\text { amplas ou específicas, abrangendo } \\
\text { abstrações de uma obra. Essas } \\
\text { abstrações podem ser termos } \\
\text { que identifiquem as áreas de } \\
\text { conhecimento, disciplinas, escolas } \\
\text { de pensamento, teorias; ou ainda } \\
\text { as técnicas fotográficas que podem } \\
\text { ser incorporadas as imagens desde } \\
\text { a sua concepção. }\end{array}$ \\
\hline Objeto & $\begin{array}{l}\text { Está relacionado a uma coisa } \\
\text { material, que abrange uma } \\
\text { completa categoria de coisas } \\
\text { materiais que podem incluir o } \\
\text { conteúdo de ser as uma obra: } \\
\text { objetos da natureza, objetos da } \\
\text { criação humana ou objetos que já } \\
\text { não existam. }\end{array}$ \\
\hline Evento & $\begin{array}{l}\text { Entidade que inclui as ações, } \\
\text { ocorrências ou acontecimentos que } \\
\text { derivaram ou ao que a imagem } \\
\text { se encontra, como um momento } \\
\text { histórico, época, período de tempo. }\end{array}$ \\
\hline Lugar & $\begin{array}{l}\text { É a localização ou uma série de } \\
\text { localizações como: terrestres } \\
\text { e extraterrestres, históricas ou } \\
\text { contemporâneas, características } \\
\text { geográficas e jurisdições } \\
\text { geopolíticas. }\end{array}$ \\
\hline
\end{tabular}




\begin{tabular}{|c|c|}
\hline Thema & $\begin{array}{l}\text { É uma entidade para que os } \\
\text { relacionamentos de todos os } \\
\text { assuntos se atrelarem a apenas } \\
\text { um, incorporando as entidades de } \\
\text { Conceito, Objeto, Evento e Lugar. }\end{array}$ \\
\hline Chronos & $\begin{array}{l}\text { Foi identificado nos contextos } \\
\text { e na definição dos atributos a } \\
\text { necessidade de arquivos e museus } \\
\text { em destacarem o tempo de } \\
\text { uma obra. Principalmente, para } \\
\text { Arquivologia a entidade determina } \\
\text { em questão a temporalidade } \\
\text { do recurso imagético e qual } \\
\text { forma será armazenada. Possui } \\
\text { relacionamentos de registro. }\end{array}$ \\
\hline Fysikos & $\begin{array}{l}\text { A necessidade de uma entidade } \\
\text { para propriedades físicas, parte } \\
\text { do escopo da Museologia na } \\
\text { criteriosa avaliação do estado em } \\
\text { que os recursos se encontram, no } \\
\text { caso, a imagem analógica se houve } \\
\text { alguma danificação ou outra } \\
\text { ocorrência. Possui relacionamentos } \\
\text { de estrutura. }\end{array}$ \\
\hline Rízo & $\begin{array}{l}\text { Abrange as necessidades } \\
\text { específicas para a identificação } \\
\text { da procedência e proveniência. } \\
\text { Possui relacionamentos de origem } \\
\text { e provir. }\end{array}$ \\
\hline Érgo & $\begin{array}{l}\text { Corresponde as atividades } \\
\text { que necessitam ser relatadas, } \\
\text { como a classificação, avaliação e } \\
\text { curadoria. Possui relacionamentos } \\
\text { de composição. }\end{array}$ \\
\hline
\end{tabular}

Fonte: Adaptado de Simionato (2015, p. 122-132).

Algumas entidades, principalmente as correspondentes ao Grupo 3, possibilitam que a descrição seja utilizada a partir dos EXIF como fonte de informação. No entanto, para que seja evitada anomalias de alguns atributos, o quadro 2 apresenta cada entidade, os relacionamentos e seus respectivos atributos, que serão utilizados para a descrição das entidades de forma integral, já previstos pela etapa anterior no crosswalk realizado.
Quadro 2 - Atribuição de metadados para cada entidade e relacionamento da modelagem DILAM

\begin{tabular}{|c|c|}
\hline ENTIDADE & ATRIBUTO \\
\hline Obra & $\begin{array}{c}\text { Data de criação* } \\
\text { Data relacionada ao título } \\
\text { Nome(s) do(s) produtor(es)* } \\
\text { Nota descritiva* } \\
\text { Título * } \\
\text { Título do criador }\end{array}$ \\
\hline Obra-obra & $\begin{array}{c}\text { Tipo de relacionamento* } \\
\text { Descrição da derivação* } \\
\text { Extensão do autor } \\
\text { Qualificação do autor } \\
\text { Título do autor* } \\
\text { Data* } \\
\text { Data de criação* } \\
\text { Data relacionada ao título } \\
\text { Localização da criação* } \\
\text { Notas* }\end{array}$ \\
\hline Expressão & $\begin{array}{c}\text { Data de criação* } \\
\text { Data de relação a obra* } \\
\text { Data relacionada ao título } \\
\text { Data* } \\
\text { Descrição da derivação } \\
\text { Descrição da edição* } \\
\text { Nome(s) do(s) produtor(es)* } \\
\text { Nota descritiva* } \\
\text { Número da edição } \\
\text { Número de identificação* } \\
\text { Tipo de relação a obra } \\
\text { Título equivalente* } \\
\text { Título da expressão* } \\
\text { Título do criador* } \\
\text { Notas* }\end{array}$ \\
\hline $\begin{array}{l}\text { Expressão- } \\
\text { expressão }\end{array}$ & $\begin{array}{c}\text { Descrição da derivação } \\
\text { Descrição da edição* } \\
\text { Idioma* } \\
\text { Notas* }^{*} \\
\end{array}$ \\
\hline Expressão-obra & $\begin{array}{c}\text { Data* }^{*} \\
\text { Data de criação* } \\
\text { Data relacionada ao título* } \\
\text { Idioma* } \\
\text { Notas* }^{*}\end{array}$ \\
\hline Manifestação & $\begin{array}{c}\text { Data de criação* } \\
\text { Data relacionada ao título } \\
\text { Nome(s) do(s) produtor(es)* } \\
\text { Nota descritiva* } \\
\text { Título da manifestação* } \\
\text { Designação de edição/impressão } \\
\text { Local de publicação/distribuição } \\
\text { Publicador/distribuidor } \\
\text { Data de publicação/distribuição } \\
\text { Fabricante } \\
\text { Indicação de série } \\
\text { Forma do suporte } \\
\text { Extensão do suporte } \\
\text { Meio físico } \\
\text { Modo de captura } \\
\text { Dimensões do suporte } \\
\text { Identificador da Manifestação } \\
\text { Fonte para aquisição/autorização de } \\
\text { acesso } \\
\text { Notas* }\end{array}$ \\
\hline
\end{tabular}




\begin{tabular}{|c|c|}
\hline $\begin{array}{l}\text { Manifestação- } \\
\text { manifestação }\end{array}$ & $\begin{array}{c}\text { Data de criação* } \\
\text { Data relacionada ao título } \\
\text { Notas* }\end{array}$ \\
\hline Item & $\begin{array}{c}\text { Identificador do item* } \\
\text { Impressão digital } \\
\text { Restrições de acesso ao item* } \\
\text { Localização do item* } \\
\text { Notas* }^{*}\end{array}$ \\
\hline $\begin{array}{c}\text { Item- } \\
\text { manifestação }\end{array}$ & $\begin{array}{l}\text { Data de criação* } \\
\text { Localização* }^{*} \\
\text { Notas* }^{*}\end{array}$ \\
\hline Item-item & $\begin{array}{c}\text { Data de criação* } \\
\text { Localização* }^{*} \\
\text { Notas* }^{*}\end{array}$ \\
\hline Pessoa & $\begin{array}{c}\text { Nome da Pessoa* } \\
\text { Datas da Pessoa } \\
\text { Título da Pessoa } \\
\text { Outra designação associada à Pessoa } \\
\text { Notas* }\end{array}$ \\
\hline Família & $\begin{array}{c}\text { Nome da Família* } \\
\text { Datas da Família } \\
\text { Título da Família } \\
\text { Outra designação associada à Família } \\
\text { Notas* }\end{array}$ \\
\hline Entidade coletiva & $\begin{array}{c}\text { Nome da Entidade Coletiva* } \\
\text { Número associado à Entidade Coletiva } \\
\text { Local associado à Entidade Coletiva } \\
\text { Data associada à Entidade Coletiva } \\
\text { Outra designação associada à Entidade } \\
\text { Coletiva } \\
\text { Notas* }\end{array}$ \\
\hline $\begin{array}{l}\text { Responsabili- } \\
\text { dade }\end{array}$ & $\begin{array}{c}\text { Data de Falecimento* } \\
\text { Data de Nascimento* } \\
\text { Nacionalidade* } \\
\text { Nome da fonte das informações } \\
\text { inseridas } \\
\text { Nome da Pessoa, Família ou Entidade } \\
\text { Coletiva* } \\
\text { Nota biográfica da pessoa } \\
\text { Pessoas vinculadas à Pessoa, Família ou } \\
\text { Entidade Coletiva } \\
\text { Profissão da pessoa* } \\
\text { Sexo* } \\
\text { Notas* }^{*}\end{array}$ \\
\hline Conceito & $\begin{array}{c}\text { Assunto principal de conceito* } \\
\text { Data atribuída ao assunto* } \\
\text { Notas* }\end{array}$ \\
\hline Objeto & $\begin{array}{l}\text { Assunto principal de objeto* } \\
\text { Notas* }\end{array}$ \\
\hline Evento & $\begin{array}{c}\text { Assunto principal de evento* } \\
\text { Data do evento* } \\
\text { Estilo do período histórico } \\
\text { Notas* }^{*}\end{array}$ \\
\hline Lugar & $\begin{array}{c}\text { Assunto principal de lugar* } \\
\text { Contexto arqueológico } \\
\text { Contexto arquitetônico } \\
\text { Locais relacionados } \\
\text { Local do evento* } \\
\text { Localização histórica } \\
\text { Tipo de evento - cultural } \\
\text { Tipo de evento - histórico } \\
\text { Tipo do período histórico* } \\
\text { Notas* }\end{array}$ \\
\hline
\end{tabular}

\begin{tabular}{|c|c|}
\hline Thema & $\begin{array}{c}\text { Descrição do conteúdo - atividade } \\
\text { Descrição do conteúdo - objeto } \\
\text { Escopo e conteúdo* } \\
\text { Nota descritiva do assunto* } \\
\text { Notas* } \\
\text { Termos de indexação* } \\
\text { Termos genéricos* } \\
\text { Termos técnicos de iconografia } \\
\text { Notas* }\end{array}$ \\
\hline Chronos & $\begin{array}{c}\text { Descrição sobre a temporalidade* } \\
\text { Datas associadas a manifestação } \\
\text { Datas associadas a expressão } \\
\text { Notas* }^{*}\end{array}$ \\
\hline Fysikos & $\begin{array}{c}\text { Abertura da lente } \\
\text { Coloração* } \\
\text { Compensação de exposição } \\
\text { Contraste* } \\
\text { Descrição das dimensões* } \\
\text { Distância focal } \\
\text { Extensão* } \\
\text { Flash* } \\
\text { Forma* } \\
\text { Formato / Tamanho* } \\
\text { ISO* } \\
\text { Marcas d'água* } \\
\text { Materiais / Técnicas de Descrição* } \\
\text { Materiais / Técnicas de Extensão* } \\
\text { Nitidez* } \\
\text { Orientação* } \\
\text { Saturação* } \\
\text { Tamanho } \\
\text { Tipo de extensão* } \\
\text { Tipo de dimensões } \\
\text { Unidade das dimensões } \\
\text { Valor das dimensões* } \\
\text { Condição do Item } \\
\text { Histórico de tratamento } \\
\text { Plano de tratamento } \\
\text { Notas* }\end{array}$ \\
\hline Rízo & $\begin{array}{c}\text { Descrição da procedência* } \\
\text { Descrição da proveniência } \\
\text { Estatuto Jurídico relacionado } \\
\text { História administrativa/Biografia do } \\
\text { Criador/Produtor* } \\
\text { História da custódia* } \\
\text { Procedência* } \\
\text { Proveniência do Item } \\
\text { Marcas/inscrições } \\
\text { Histórico de exibição } \\
\text { Notas* } \\
\end{array}$ \\
\hline Érgo & $\begin{array}{c}\text { Descrição do proprietário / agente* } \\
\text { Descrição sobre avaliação e eliminação } \\
\text { Descrição sobre o sistema de arranjo* } \\
\text { Características físicas e requisitos }^{*} \text { técnicos* } \\
\text { Condições de acesso* } \\
\text { Condições de reprodução } \\
\text { Direitos autorais* } \\
\text { Notas* }^{*}\end{array}$ \\
\hline
\end{tabular}

Fonte: Simionato, 2015, p. 133-136.

Os atributos com o asterisco $\left(^{*}\right)$ foram julgados como metadados obrigatórios e que são importantes para a identificação da entidade.

O processo de correspondência estará vinculado a padrões de metadados que subsidiam 
uma estrutura, ou seja, o formato para construção do registro. Por essa razão, em alguns momentos do crosswalk para os padrões de metadados específicos da Arquivologia, Biblioteconomia, Museologia e também para os recursos imagéticos digitais, um metadado corresponderá a muitos outros metadados do outro padrão, em diferentes casos poderão ocorrer que diversos metadados serão direcionados a apenas outro do padrão de destino ou então, um metadado não corresponderá a nenhum outro e assim, o metadado não será utilizado.

\section{CONSIDERAÇÕES FINAIS}

Considera que em virtude das novas necessidades de vinculação e integração de dados, essa pesquisa traz uma abordagem para o contexto em que já vivenciamos e conhecemos, a descrição em arquivos, bibliotecas e museus.

Nesse sentido, o modelo DILAM é uma proposta que acrescenta mais entidades já vistas no Requisitos Funcionais para Recursos Imagéticos Digitais (RFDID), apreciando as necessidades fundamentais dos contextos já explicitados, principalmente quando uma das questões fundamentais é produção do item informacional.

Referente ao item informacional, ressalta-se a discrepância e as precauções para cada contexto. Em bibliotecas, o item pode ter várias cópias que possuem o mesmo processo documental - os exemplares, ao contrário do que acontece em arquivos e museus. Os cuidados com o recurso imagético para a Arquivologia e a Museologia são no sentido que os documentos são tratados como únicos e não há exemplares, apenas cópias ou réplicas. Além disso, nesses dois casos há uma importância maior: o vínculo com o criador ou produtor, no qual é decisivo para incorporação na coleção.

A construção do modelo DILAM foi baseado nos principais modelos conceituais já consolidados e por isso, as principais entidades não teriam grandes ajustes em relação a persistência e consistência de dados. Isso quer dizer, que seja para um banco de dados, uma base de um catálogo cooperativo, é possível que contenha diversos tipos de abstrações com a mesma base conceitual. Isso pode ainda mais criar a interoperabilidade sintática de diversos tipos de recursos informacionais, bibliográficos, imagéticos, fílmicos, entre outros, em uma mesma base e catálogo.

Indica que o sentido desta interlocução entre as instituições não converge à unificação, pois cada contexto mostra diferenças. Mas é importante expressar e destacar por meio do modelo DILAM como isso pode ser colaborativo e cooperativo em relação aos avanços tecnológicos presentes na representação e organização da informação.

Artigo recebido em 30/09/2016 e aceito para publicação em 19/06/2017

\section{DILAM CONCEPTUAL MODEL: integration of archives, libraries and museums}

ABSTRACT Descriptive principles in archives, libraries and museums present diverse procedures and are consistent with the ways in which their resources are represented, mainly in relation to the description of the image content. In this way, the research problem involves the question of how to promote the integration of the contexts of Archivology, Librarianship and Museology for the digital image resource? The integration proposal between the contexts seeks the convergence of the data of the image treated in the Archivology, Librarianship and Museology, benefiting the recovery and location of the resources by the user. It points out the digital medium and the descriptive principles of the three contexts as factors that subsidize the studies and development of a conceptual model. Thus, the objective of this work is to present the results of this proposal, through the construction of the conceptual model Digital Images for Libraries, Archives and Museums (DILAM) emphasizing their entities and the attributes responsible for the integration to the contexts and the digital image resource. Methodologically it constitutes an applied and exploratory theoretical research. It addresses the entities and attributes of the conceptual model DILAM, in addition to the groups concerning the integration of contexts and the properties of the image content. It is considered that this structure is presented in the integration diagram applicable in the digital environment in which libraries, archives and museums can cooperate by reusing the data and reducing the reworking of the description of digital image resources.

Keywords: $\quad$ Digital image. Representation of information. Metadata. 


\section{REFERÊNCIAS}

BACA, M. (ED.). Introduction to metadata. $2 \mathrm{ed}$. Los Angeles, CA: Getty Research Institute, 2008.

BARBUY, H. Os museus e seus acervos: sistemas de documentação em desenvolvimento. INTEGRAR: $1^{\circ}$ Congresso Internacional de Arquivos, Bibliotecas, Centros de Documentação e Museus. Anais... In: ANAIS... São Paulo: Imprensa Oficial do Estado, 2002

CAMARGO-MORO, F. Museu: aquisiçãodocumentação. Rio de Janeiro: Livraria Eça, 1986.

GLUSHKO, R. J. The discipline of organizing. 1 ed. Massachusetts, EUA: The MIT Press, 2013.

GUIMARÃES, J. A. C. Ciência da Informação, arquivologia e biblioteconomia: em busca do necessário diálogo entre o universo teórico e os fazeres profissionais. In: Ensino e Pesquisa em Biblioteconomia no Brasil: A emergência de um novo olhar. São Paulo: Cultura Acadêmica. Marília: UNESP. p. 31-43.

GUINCHAT, C.; MENOU, M. Introdução geral às ciências e técnicas da informação $\mathrm{e}$ documentação. Brasília: MCT/CNPq/IBICT, 1994.

HOMULOS, P. Museums to libraries: a family of collecting institutions. Art libraries journal, v. 15, n. 01, p. 11-13, 1990.

MARCONDES, C. H. Linked data - dados interligados - e interoperabilidade entre arquivos, bibliotecas e museus na web. Encontros Bibli: revista eletrônica de biblioteconomia e ciência da informação, v. 17, n. 34, 9 ago. 2012.

PIERRE, M. S.; LAPLANT, W. P. Issues in crosswalking content metadata standards. Information standards quarterly, v. 11, n. 1, p. 01-16, 1999.

ROUSSEAU, J.-Y.; COUTURE, C. Os fundamentos da disciplina arquivística. Lisboa: Publicações Dom Quixote Lisboa, 1998.

SÁNCHEZ VIGIL, J. M. El documento fotográfico: historia, usos, aplicaciones. Madri: Ediciones Trea, 2006.
SANTOS, P. L. V. A. DA C.; PEREIRA, A. M. Catalogação: breve história e contemporaneidade. Niterói (RJ): Intertexto, 2014.

SANTOS, P. L. V. A. DA C.; SIMIONATO, A. C.; ARAKAKI, F. A. Definição de metadados para recursos informacionais: apresentação da metodologia BEAM. Informação \& Informação, v. 19, n. 1, p. 146, 25 fev. 2014.

SIMIONATO, A. C. Representação, acesso, uso e reuso da imagem digital. Dissertação (Mestrado em Ciência da Informação)-Marília (SP): Universidade Estadual Paulista, Faculdade de Filosofia e Ciências, 2012.

SIMIONATO, A. C. Modelagem conceitual DILAM: princípios descritivos de arquivos, bibliotecas e museus para o recurso imagético digital. Tese-Marília/SP: Universidade Estadual Paulista, Faculdade de Filosofia e Ciências, 2015.

SMIT, J. W. O documento audiovisual ou a proximidade entre as 3 Marias. RBBD, v. 26, n. 1/2, p. 81-1001, 2009.

SMIT, J. W.; BARRETO, A. DE A. Ciência da Informação: base conceitual para a formação do profissional. Formação do profissional da informação. São Paulo: Polis, p. 9-23, 2002.

SVENONIUS, E. The intellectual foundation of information organization. First: MIT Press, Cambridge, Mass.: MIT Press, 2009.

TANUS, G. F. DE S. C.; ARAÚJO, C. A. Á. Proximidades conceituais entre arquivologia, biblioteconomia, museologia e ciência da informação. Biblionline, v. 8, n. 2, 2012.

ZOREDA, L. C. La documentación museológica. Boletín de la ANABAD, v. 38, n. 4, p. 455-496, 1988. 